\title{
Core models of receptor reactions to evaluate basic pathway designs enabling heterogeneous commitments to apoptosis
}

\author{
Marielle Péré ${ }^{1,2}$, Madalena Chaves ${ }^{1}$, and Jérémie Roux ${ }^{1,2}$ \\ 1 Université Côte d'Azur, Inria, INRAE, CNRS, Sorbonne Université, Biocore team, \\ Sophia Antipolis, France \\ 2 Université Côte d'Azur, CNRS UMR 7284, Inserm U 1081, Institut de Recherche \\ sur le Cancer et le Vieillissement de Nice, Centre Antoine Lacassagne, 06107 Nice,
}

France

\begin{abstract}
Isogenic cells can respond differently to cytotoxic drugs, such as the tumor necrosis factor-related apoptosis inducing ligand (TRAIL), with only a fraction committing to apoptosis. Since non-genetic transient resistance to TRAIL has been shown to dependent on caspase- 8 dynamics at the receptor level in vitro, here we investigate the core reactions leading to caspase- 8 activation, based on mass-action kinetics models, to evaluate the basic mechanisms giving rise to the observed heterogeneous response. In this work, we fit our models to single-cell trajectories of time-resolved caspase- 8 activation measured in clonal cells after treatment with TRAIL. Then, we analyse our results to assess the relevance of each model and evaluate how well it captures the extent of biological heterogeneity observed in vitro. Particularly, we focus on a positive feedback loop on caspase- 8 , the impacts of initial condition variations and the relevance of the caspase- 8 degradation.
\end{abstract}

Keywords: ODE - Mass-action kinetics - Parameter identification . Apoptosis · Fractional killing · TRAIL · Caspase-8.

\section{Introduction}

Apoptosis plays a key role in human tissue homeostasis. Its disruption causes well-known diseases such as Alzheimer, Parkinson (excessive apoptosis), or autoimmune disorders and cancers (lack of apoptosis).

To induce cell death in tumor cells, many treatments have been designed and tested so far, such as TRAIL-receptor ligands, which present the advantage of sparing healthy cells. TRAIL binds the death receptors (DR4/5) of the cancer cell, initiating the extrinsic apoptosis pathway. Then, a Death-Inducing Signaling Complex (DISC) is formed in the cytoplasm with adaptor-proteins such as FADD (Fas-Associated protein with Death Domain). This association allows the recruitment of the pro-caspase 8 and 10 (hereafter $\mathrm{pC} 8$ and $\mathrm{pC} 10$ ) and other proteins. These pro-caspases compete at the DISC level with c-FLIP [8], an anti-apoptotic protein, to activate the initiator caspase 8 (C8) [31] via 
dimerization (or even trimerization) and self-cleavage of pC8 [19]. In many cell types, once activated, C8 triggers cell death by mediating Bid cleavage causing the mitochondrial outer membrane permeabilization (MOMP, 4]) which induces the activation of the effective caspases 3 and 7 (C3 and C7), or "executioner caspase", leading to DNA fragmentation and cell death [21/30.

Although TRAIL has been a very promising drug thanks to its ability to target cancer cells specifically, it showed only limited success in the clinic due to a lack of efficiency. In fact, single-cell studies revealed that cells from the same clonal population commit differently to cell death when treated with TRAIL (or other pro-apoptotic drugs), with an important variability in the time of death for the sensitive cells and with a fraction of cells evading apoptosis entirely. When the remaining resistant cells are retreated a second time with cancer drugs (even saturating doses), fractional killing is once again observed. 32[33.

A number of studies and mathematical modeling efforts have evaluated the origins of drug response heterogeneity, proposing mechanisms such as the random fixation of TRAIL on the DR4/5 [1]3, the presence of decoy receptors (which impair the formation of a functional DISC after ligand binding [2]) or the p53 gene effects on TRAIL efficiency 24|25. The gene CD-95 has also an impact as it regulates FADD, an essential protein for the $\mathrm{pC} 8$ binding to the DISC [5]26]27|28]. c-FLIP antagonist role has been revealed as well, and gives a better understanding of how it "competes" with pC8 at DISC level to trigger (or not) apoptosis 9617/5, (even if C8 and FLIP seem to bind the DISC on different sites, pC8 favors c-FLIP recruitment [8]). The action of $\mathrm{C} 10$ is less well identified. It may be an anti-apoptotic factor in some cases [10, as some members of Bcl-2 family that competes for activating MOMP downstream 30|21]4. But C10 has also a pro-death role [1112, it can trigger apoptosis in absence of C8 13]14 and favor anti-tumorigenesis [15]. Finally, C8 activation has been defined as a determining factor in cell death decision [16, by showing a threshold in rate and timing for $\mathrm{C} 8$ activation that distinguishes resistant and sensitive cells [17].

These studies lead to the conclusion that cell decision happens before MOMP and the effector caspase cascade.

Here, taking these insights into consideration with $\mathrm{C} 8$ threshold as the main determinant of cell fate, we aim to identify within the core reactions, basic pathway designs that capture cell response heterogeneity to TRAIL, and features of C8 dynamics. Once identified, the next goal is to characterize these regulatory events, to understand how and to what extent, some proteins may influence the $\mathrm{C} 8$ dynamic and determine how their variation is correlated to the cell-to-cell variability.

In that aim, we especially focus on three points: (i) FADD role and its capacity for regulating $\mathrm{C} 8$, (ii) the relevance of caspase clusters composed of $\mathrm{C} 8$ and $\mathrm{C} 10$, and (iii) the regulatory effect of the effector caspases on $\mathrm{C} 8$ which depends on a positive feedback loop. To investigate the effect of these interactions and their relative timing on apoptosis, we then propose four alternative minimal ODE models. Next, based on the results of Roux and al. [17, these models are calibrated from single-cell data and the distributions of the different 
parameters are analysed to find links between the models, the C8 dynamic and the cell fates. Finally, we study the feedback loop action, quantify the influence of FADD and C10 and validate our models, explaining the special distribution of C8 degradation.

\section{Modeling the main processes of extrinsic apoptosis initiation}

The first goal is to establish the mechanisms responsible for the main pathway dynamics, and their impact on the $\mathrm{C} 8$ activation threshold distinguishing between TRAIL resistant and sensitive cells. The second aim is to understand how these these mechanistic models can reproduce cell response heterogeneity.

To this end, this study focuses on three different regulation points : the FADD protein and its capacity for regulation of $\mathrm{C} 8$, the importance of $\mathrm{C} 8 / \mathrm{C} 10$ cluster in $\mathrm{C} 8$ activation [10] and the possible presence of a dowstream regulatory effect of C8 [2130], symbolized here by a positive feedback loop from the effector caspase cascade on the $\mathrm{C} 8$. In each case, our analyses aim to understand the effect of a given mechanism on the $\mathrm{C} 8$ dynamics main features and in which measure this process is a source of heterogeneity or, at least, source of extrinsic noise.

\subsection{Models' assumptions}

To capture the extrinsic apoptosis core reactions, our models are thus constructed with a minimal number of components and steps : the TRAIL binding on the death-receptor DR $4 / 5$, the recruitment of the FADD protein and the initiator $\mathrm{pC} 8$ to form the DISC, the $\mathrm{pC} 8$ dimerization, and finally the activation of C8. (c-FLIP is considered to be in very small quantities and so has a lower impact on $\mathrm{C} 8$ recruitment.)

TRAIL is denoted by $\mathrm{T}$, the DR4/5 receptors become a single component named $\mathrm{R}$ (for Receptor), the $\mathrm{pC} 8$ and $\mathrm{C} 8$ are grouped to form a unique protein $\mathrm{C} 8$. Instead of the recruitment of a single pC8, our models assume two molecules simultaneously bind to DISC, since only dimerization or trimerization of $\mathrm{pC} 8$ can trigger apoptosis. $\mathrm{F}_{D}$ denotes the FADD protein and $Z_{0}$ the complex TRAIL-receptors. The downstream caspase cascade, the MOMP and cell death are grouped into the component $\mathrm{D}$, with a intermediary complex $Z_{1}$.

\subsection{Extrinsic apoptosis initiation core models (EAICM)}

Four extrinsic apoptosis initiation core models (EAICM) are proposed, corresponding to the four possible combinations of presence or not of a feedback loop on $\mathrm{C} 8$ conjugated with either the adaptor protein or $\mathrm{C} 8 / \mathrm{C} 10$ binding.

The feedback loop is represented by the red links on Figure 1. Two models focus on $\mathrm{C} 10 / \mathrm{C} 8$ coupling, where the $\mathrm{C} 8$ dimerization happens before the $\mathrm{C} 10$ binding (models -cf and -c) to understand how $\mathrm{C} 10$ interacts with $\mathrm{C} 8$, and finally two others, where only the FADD reaction and the $\mathrm{C} 8$ dimerization are taken into 


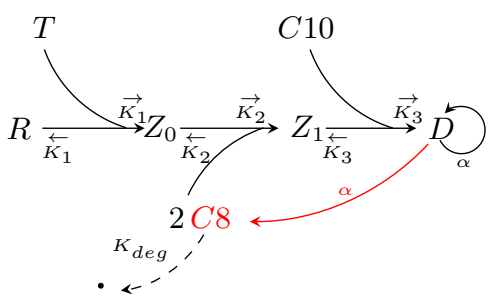

(a) EAICM-cf

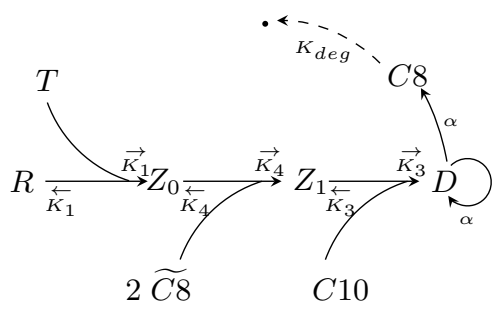

(c) EAICM-c

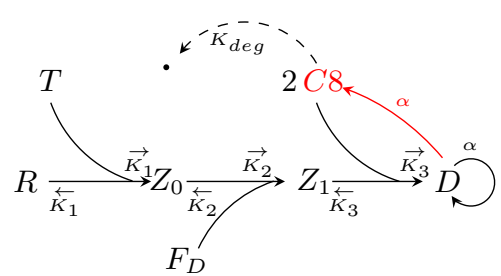

(b) EAICM-af

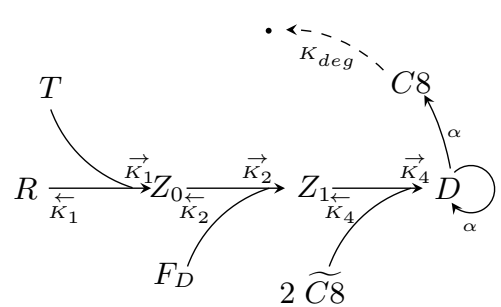

(d) EAICM-a

Fig. 1: Extrinsic apoptosic initiation core models (EAICM) schemes

account (models -af and -a) to examine the importance of the adaptor protein FADD, especially its regulatory capacity of $\mathrm{pC} 8$ recruitment.

In models without feedback loop, $\widetilde{C 8}$ is a constant parameter representing available $\mathrm{pC} 8$.

To model the different reactions, we apply the mass-action kinetics and obtain four models of the form $d X / d t=f_{P_{r}}(X)$, with $f: \mathbb{R}^{7} \rightarrow \mathbb{R}^{7}$ depending on the time-independent reaction rate vector $P_{r}=\left(\vec{K}_{1}, \overleftarrow{K_{1}}, \ldots, \alpha\right)$, and the initial conditions:

$$
\left\{\begin{array}{l}
X_{0}^{c}=\left(T_{0}, R_{0}, C 8_{0}, C 10_{0}, Z_{0,0}, Z_{1,0}, D_{0}\right) \\
X_{0}^{a}=\left(T_{0}, R_{0}, C 8_{0}, F_{D, 0}, Z_{0,0}, Z_{1,0}, D_{0}\right)
\end{array}\right.
$$

EAICM-cf:

$$
\left\{\begin{aligned}
\frac{d T}{d t} & =-\vec{K}_{1} T R+\overleftarrow{K_{1}} Z_{0} \\
\frac{d R}{d t} & =-\vec{K}_{1} T R+\overleftarrow{K_{1}} Z_{0} \\
\frac{d Z_{0}}{d t} & =\vec{K}_{1} T R-\overleftarrow{K_{1}} Z_{0}-\vec{K}_{2} Z_{0} C 8^{2}+\overleftarrow{K_{2}} Z_{1} \\
\frac{d C 8}{d t} & =-2 \vec{K}_{2} Z_{0} C 8^{2}+2 \overleftarrow{K_{2}} Z_{1}+\alpha D-K_{d e g} C 8 \\
\frac{d Z_{1}}{d t} & =\vec{K}_{2} Z_{0} C 8^{2}-\overleftarrow{K_{2}} Z_{1}-\vec{K}_{3} Z_{1} C 10+\overleftarrow{K_{3}} D \\
\frac{d C 10}{d t} & =-\vec{K}_{3} C 10 Z_{1}+\overleftarrow{K_{3}} D \\
\frac{d D}{d t} & =\vec{K}_{3} Z_{1} C 10-\overleftarrow{K_{3}} D
\end{aligned}\right.
$$

\section{EAICM-af:}

$$
\left\{\begin{aligned}
\frac{d T}{d t} & =-\vec{K}_{1} T R+\overleftarrow{K_{1}} Z_{0} \\
\frac{d R}{d t} & =-\vec{K}_{1} T R+\overleftarrow{K_{1}} Z_{0}, \\
\frac{d Z_{0}}{d t} & =\vec{K}_{1} T R-\overleftarrow{K_{1}} Z_{0}-\vec{K}_{2} Z_{0} F_{D}+\overleftarrow{K_{2}} Z_{1}, \\
\frac{d F_{D}}{d t} & =-\vec{K}_{2} F_{D} Z_{0}+\overleftarrow{K_{2}} Z_{1} \\
\frac{d Z_{1}}{d t} & =\vec{K}_{2} Z_{0} F_{D}-\overleftarrow{K_{2}} Z_{1}-\vec{K}_{3} Z_{1} C 8^{2}+\overleftarrow{K_{3}} D \\
\frac{d C 8}{d t} & =-2 \vec{K}_{3} Z_{1} C 8^{2}+2 \overleftarrow{K_{3}} D+\alpha D-K_{d e g} C 8 \\
\frac{d D}{d t} & =\vec{K}_{3} Z_{1} C 8^{2}-\overleftarrow{K_{3}} D .
\end{aligned}\right.
$$


EAICM-c:

$$
\left\{\begin{aligned}
\frac{d T}{d t} & =-\vec{K}_{1} T R+\overleftarrow{K_{1}} Z_{0}, \\
\frac{d R}{d t} & =-\vec{K}_{1} T R+\overleftarrow{K_{1}} Z_{0}, \\
\frac{d Z_{0}}{d t} & =\vec{K}_{1} T R-\overleftarrow{K_{1}} Z_{0}-\vec{K}_{4} Z_{0} \widetilde{C 8}^{2}+\overleftarrow{K}_{4} Z_{1}, \\
\frac{d C 8}{d t} & =\alpha D-K_{d e g} C 8 \\
\frac{d Z_{1}}{d t} & =\vec{K}_{4} Z_{0} \widetilde{C 8}^{2}-\overleftarrow{K_{4}} Z_{1}-\vec{K}_{3} Z_{1} C 10+\overleftarrow{K_{3}} D \\
\frac{d C 10}{d t} & =-\vec{K}_{3} C 10 Z_{1}+\overleftarrow{K_{3}} D, \\
\frac{d D}{d t} & =\vec{K}_{3} Z_{1} C 10-\overleftarrow{K_{3}} D .
\end{aligned}\right.
$$

EAICM-a:

$$
\left\{\begin{aligned}
\frac{d T}{d t} & =-\vec{K}_{1} T R+\overleftarrow{K}_{1} Z_{0}, \\
\frac{d R}{d t} & =-\vec{K}_{1} T R+\overleftarrow{K}_{1} Z_{0}, \\
\frac{d Z_{0}}{d t} & =\vec{K}_{1} T R-\overleftarrow{K}_{1} Z_{0}-\vec{K}_{2} Z_{0} C 10+\overleftarrow{K_{2}} Z_{1}, \\
\frac{d F_{D}}{d t} & =-\vec{K}_{2} F_{D} Z_{0}+\overleftarrow{K_{2}} Z_{1}, \\
\frac{d Z_{1}}{d t} & =\vec{K}_{2} F_{D} Z_{0}-\overleftarrow{K}_{2} Z_{1}-\vec{K}_{4} Z_{1} \widetilde{C 8}^{2}+\overleftarrow{K_{4}} D \\
\frac{d C 8}{d t} & =\alpha D-K_{d e g} C 8 \\
\frac{d D}{d t} & =\vec{K}_{4} Z_{1} \widetilde{C 8}^{2}-\overleftarrow{K_{4}} D .
\end{aligned}\right.
$$

Comparing these four alternatives to experimental measurements is then necessary to investigate which of the mechanisms more faithfully reproduces the data and is capable of better generating the single-cell dynamic properties.

\section{Single cell model calibration}

Our models are calibrated using single cell data from Roux and al. 17. The data measure the C8 activity before MOMP happens for 414 single cells (114 resistant and 300 sensitive) treated only with $50 \mathrm{ng} / \mathrm{mL}$ of TRAIL (and not with cycloheximide contrary to [2130]), for 10 hours. These data were obtained using the Initiator Caspase-Reporter Protein (IC-RP [21]), a FRET pair of fluorescent proteins that are linked by the peptide sequence of Bid, cleaved by C8. (FRET therefore decreases once IC-RP molecules are cleaved by C8.) In the same time, Bid is cleaved in tBid, which regulates MOMP in extrinsic apoptosis. As there is no degradation of IC-RP, contrary to tBid, it accumulates leading to the FRET stabilization at the end of the experiment for resistant cells that corresponds to the tBid degradation.

The four EAIC models are fitted to each single cell traces separately, as opposed to fitted to one averaged trace 4142. This approach is meant to study each single cell's heterogeneous features and it allows to obtain the parameter distribution without any assumption.

One model topology is used for both resistant and sensitive cells, since the clonal cells are genetically homogeneous. (The main differences between the two populations are attributed to the protein expression levels.)

As only data on the evolution of FRET ratio in time is available, and because the models do not take into account the FRET activation, we assume that the FRET creation corresponds only to a re-scale of $\mathrm{C} 8$, ie that the FRET dynamic is obtained from the $\mathrm{C} 8$ dynamic by changing the amplitude of the $\mathrm{C} 8$ curve and the activation time with a supplementary delay, and so the method compares directly the implemented $\mathrm{C} 8$ concentration to the real cleaved $\mathrm{C} 8$, with great attention to the slope as the FRET slope is a major indicator of the C8 activation speed. 


\subsection{From qualitative criteria to quantitative reference values}

To evaluate and compare the four models, it is essential to define a set of criteria to determine how closely each model approaches the real data. This involves translating the main qualitative properties of the $\mathrm{C} 8$ curves into quantitative values that can be calculated from the model's solutions. Three fundamental properties are relevant in $\mathrm{C} 8$ dynamic and can be evaluated as reference values, as follows (see Figure 2):

(i) the time delay before activation of $\mathrm{C} 8$ is triggered; (ii) the mean slope during the $\mathrm{C} 8$ activation phase; and (iii) the $\mathrm{C} 8$ concentration reaches a stabilization value, over the last 300 minutes (especially for resistant cells). These properties can be turned into reference values by defining:

- $T_{100000}$ evaluates the initial delay by $\mathrm{C} 8\left(T_{100000}\right)=100000$ molecules;

- $S$ is the C8 activation slope, as the maximum of the derivative of $\mathrm{C} 8(\mathrm{t})$ between 25 and 275 minutes, computed using the Matlab function sgolayfilt;

- $V_{\text {final }}$ gives the final stabilization value, ie C8(600), or the value of C8 at death time, for sensitive cells.

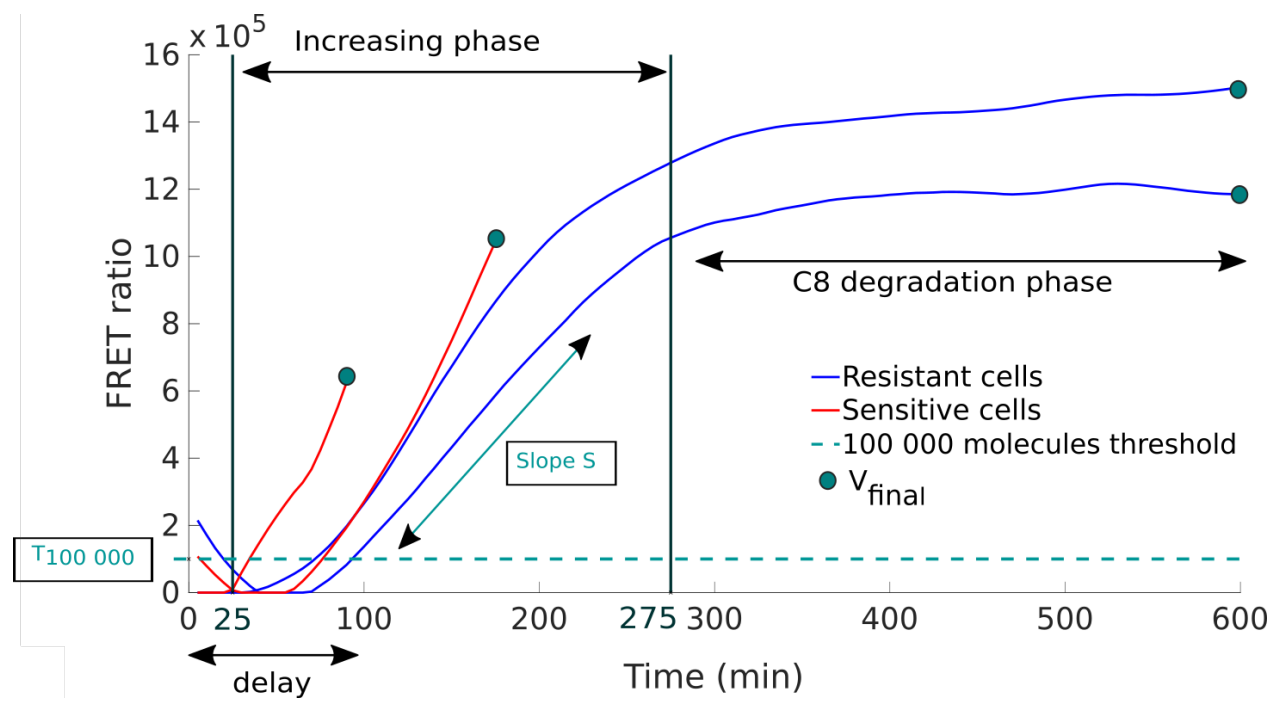

Fig. 2: Reference values and C8 features scheme

It must be noticed that the initial decreasing phase isn't taken into account. It is due to the photoactivation of the FRET and doesn't depend on the apoptosis initiation and as a result, of our models.

\subsection{Distinguishing the effects of initial conditions and rate parameters on the system dynamics}

Here, we use a nonlinear least-squares method to determine the parameters $P=\left(P_{r}, P_{i}^{j}, j \in\{c, a\}\right)$ of our models $d X / d t=f_{P_{r}}(X), P_{i}^{j} \in X_{0}$, where $P_{r}=$ 
$\left(\overleftarrow{K}_{1}, \vec{K}_{1}, \ldots, K_{d e g}, \alpha\right)$ represents the reaction rates and $P_{i}^{c}=\left(R_{0}, C 8_{0}, C 10_{0}\right)$ and $P_{i}^{a}=\left(R_{0}, C 8_{0}, F_{D, 0}\right)$ represent the initial conditions to be evaluated during the model fit, of models EAICM-cf or EAICM-af, respectively. The other initial conditions are fixed with values from literature [21].

An euclidean norm is used to compute the cost, given by the differences between the measurements, denoted by $\mathrm{C} 8_{t_{i}}, t_{i} \in \mathbb{T}=\{5,10, \ldots, 600\}$ and the computed solution $\mathrm{C} 8^{c}$ of the chosen model taken every 5 minutes. To take into account the slope and the final $\mathrm{C} 8$ concentration relevance, the cost is weighted from the $25^{\text {th }}$ min (approximately the beginning time of the increasing phase) until the end with heavier weight $\omega$ between the $25^{\text {th }}$ and the $275^{\text {th }}$ (for the slope calculated during the increasing phase). For instance, $\omega=1000$ between min 25 and $\min 275$. After $280 \mathrm{~min}, \omega=500$. Finally, denoted $T_{d}$, the cell death time, the $\operatorname{cost} \mathcal{C}$ is given by:

$$
\mathcal{C}^{2}=\sum_{t_{i} \in\left\{5, \ldots, \min \left(20, T_{d}\right)\right\}}\left(C 8_{t_{i}}-C 8_{t_{i}}^{c}\right)^{2}+\sum_{t_{i} \in\left\{25, \ldots, \min \left(275, T_{d}\right)\right\}} \omega \times\left(C 8_{t_{i}}-C 8_{t_{i}}^{c}\right)^{2}+\sum_{t_{i} \in\left\{280, \ldots, \min \left(600, T_{d}\right)\right\}} \frac{\omega}{2} \times\left(C 8_{t_{i}}-C 8_{t_{i}}^{c}\right)^{2} .
$$

Alternatively, for the resistant population, adding the squared slope difference between the data and the computed solution, improves the fit. For the sensitive population, we remove the last parts of the cost when the death time $T_{d}$ is smaller than the first boundary of the time interval for each one of the three terms of the sum. To minimize $\mathcal{C}$, we used Matlab and its function fminsearchbnb, to solve an optimization problem with a physiologically significant initial guess based on the literature. To access both the individual and joint effects of reaction rate parameters and initial conditions on the dynamics, the algorithm solves three different optimization problems,

F1. Minimize the cost $C$ with respect to both $P_{i}$ and $P_{r}$;

F2. Fix initial conditions $P_{i}$ and minimize cost $C$ with respect to $P_{r}$;

F3. Fix reaction constants $P_{r}$ and minimize cost $C$ with respect to $P_{i}$.

Fitting only initial conditions, assumes that the model is "exact" and that the response heterogeneity comes from environmental conditions and extrinsic noise only. Conversely, fitting reaction rates only, means that the models have some variability and possibly unknown or not considered reactions or proteins impact the behaviour of $\mathrm{C} 8$.

It may be expected that the heterogeneity factors are a mix of the two explanations and so the fit obtained on both initial conditions and reaction rates is the best but, in this case, the results are less straightforward to interpret.

\section{Analysing mechanisms for generating heterogeneity}

To simulate the models, we set the initial conditions for TRAIL at $T_{0}=1500$ (from [21]), and the intermediary complexes $Z_{0,0}, Z_{1,0}$ and $D_{0}$ equal to 0 .

Simulations are performed with ode23 for 600 minutes with a weight $\omega=1000$ for $\mathcal{C}$. For the parameter set and the other initial conditions, when they aren't estimated by the algorithm, values obtained during a first manual fit on a median real cell are used. 


\subsection{Comparison of the four core apoptosis models}

The first point is to elucidate which of the reactions, binding of the receptor complex to $\mathrm{F}_{D}$ or to $\mathrm{C} 10$, best reproduces the behaviour heterogeneity of $\mathrm{C} 8$. To determine which of the models of type 1 or 2 best captures the extrinsic apoptosis dynamics, the norm $\mathcal{C}$ and the reference values are computed for 114 resistant cells and 300 sensitive ones. Then, for each type of fit F1 to F3, we confront the four models by computing, for each cell and each model, the absolute value of the difference between the data slope and the $\mathrm{C} 8^{c}$ slope (that is to say $\left.\left|S_{E A I C M, i}-S_{\text {data }, i}\right|, i \in\{1, \ldots, 414\}\right)$. Then, comparing the four results for each cell, the number of cells for which each model gives the lowest result is counted. The model with the highest score (i.d. the largest number of cell for which the given model gives the lowest result comparing the four models) is considered to have the best performance, as summarized in Table 1. In Appendix A, tables for the cost $\mathcal{C}$, the $\mathrm{C} 8$ final value and the delay are given.

\begin{tabular}{|c|c|c|c|c|c|c|}
\hline \multirow{2}{*}{ F1 Model } & fate & EAICM-cf & EAICM-c & EAICM-af & EAICM-a & Best model \\
\hline \multirow{2}{*}{ F2 } & S. cells & 120 & 78 & 57 & 45 & EAICM-cf \\
\cline { 2 - 8 } & R. cells & 59 & 11 & 32 & 12 & EAICM-cf \\
\cline { 2 - 8 } & S. cells & 108 & 79 & 71 & 42 & EAICM-cf \\
\hline \multirow{2}{*}{ F3 } & R. cells & 75 & 12 & 26 & 1 & EAICM-cf \\
\cline { 2 - 8 } & S. cells & 269 & 8 & 20 & 3 & EAICM-cf \\
\hline
\end{tabular}

Table 1: Number of cell best approached per model and type of fits according to the slope

Table 1 shows clearly that EAICM-cf performs better, suggesting that the caspase cluster and the feedback loop are the main mechanisms necessary to reproduce the variability in $\mathrm{C} 8$ slope and general cell response heterogeneity. The same results are obtained for the delay criteria. Moreover, the feedback loop seems essential to capture cell C8 dynamics, because none of the models without feedback loop accurately reproduces the three $\mathrm{C} 8$ properties. This result agrees with the findings of Schwarzer and al. [36] in which they demonstrate in vivo, the downstream inducing apoptosis effectors' effects on caspase 8 . These outcomes also reveal that the clusterization of $\mathrm{C} 8 / \mathrm{C} 10$, and so the recruitment and the activation of $\mathrm{C} 8$, is more important to $\mathrm{C} 8$ dynamics than the presence of $\mathrm{F}_{D}$ in $\mathrm{pC} 8$ fixation on DISC.Tummers and al. showed that caspase- 8 mediates inflammasome activation independently of FADD in epithelial cells 38, further evidence that FADD isn't mandatory for caspase 8 activity. Future work would expand the study of this cluster reaction, perhaps adding more variables to take into account the effects of other proteins since the reactions around $\mathrm{pC} 8$ recruitment (especially its interactions with pC10 and c-FLIP) are still unclear. 
Another hypothesis could also be made in this case, assuming that in EAICMcf, the $\mathrm{F}_{D}$ action is not present in the equations but indeed taken into account since $\mathrm{C} 8$ is still recruited at the DISC level.

\subsection{The feedback loop mechanism}

The second question to address in this Section concerns the effects of the positive feedback loop on $\mathrm{C} 8$ to understand its importance on $\mathrm{C} 8$ dynamics.

To evaluate the feedback loop impacts on the $\mathrm{C} 8$ dynamic, we use the parameters obtained from fit $\mathrm{F} 1$, on both initial conditions and reaction rates. Figure 3 and Figure 4 (a) and (c) compare the FRET ratio and the $\mathrm{C} 8^{c}$ curve corresponding to the models 1 with and without feedback for selected resistant and sensitive cells from the cell populations in [17. It seems clear that the model without feedback fails to reproduce the initial delay before $\mathrm{C} 8$ activation. In a second plot, Figure 3 and Figure 4 (b) and (d) compare the relative weights of the different terms that contribute to $\mathrm{C} 8$ activation. This is a method developed by Casagranda and al. in [34] and consists in representing the absolute values curve of each term that composes the $\mathrm{C} 8$ equation, divided by the sum of all absolute values, to normalize. For instance, if we consider the following C8 equation of EAICM-cf:

$$
\frac{d C 8}{d t}=-2 \vec{K}_{2} Z_{0} C 8^{2}+2 \overleftarrow{K_{2}} Z_{1}+\alpha D-K_{d e g} C 8
$$

then the plotted curves are:

$$
\left\{\begin{array}{c}
\frac{\left|K_{\text {deg }} C 8\right|}{\left|K_{\text {deg }} C 8\right|+|\alpha D|+\left|2 \overleftarrow{K_{2}} Z_{1}\right|+\left|2 \vec{K}_{2} Z_{0} C 8^{2}\right|} \\
\frac{|\alpha D|}{\left|K_{\text {deg }} C 8\right|+|\alpha D|+\left|2 \overleftarrow{K_{2}} Z_{1}\right|+\left|2 \vec{K}_{2} Z_{0} C 8^{2}\right|} \\
\frac{\left|2 \overleftarrow{K_{2}} Z_{1}\right|}{\left|K_{\text {deg }} C 8\right|+|\alpha D|+\left|2 \overleftarrow{K_{2}} Z_{1}\right|+\left|2 \vec{K}_{2} Z_{0} C 8^{2}\right|} \\
\frac{\left|2 \vec{K}_{2} Z_{0} C 8^{2}\right|}{\left|K_{\text {deg }} C 8\right|+|\alpha D|+\left|2 \overleftarrow{K_{2}} Z_{1}\right|+\left|2 \vec{K}_{2} Z_{0} C 8^{2}\right|}
\end{array}\right.
$$

Similar plots for the EAICM-af and EAICM-a models can be found in Appendix B. First, comparing Figure 3 and Figure 4 notice that there are essentially no differences between resistant and non resistant cells in the componentwise analysis. However, there is no activation delay in $\mathrm{C} 8$ curve for the models without a feedback loop. Then, focusing on the $|\alpha \mathrm{D}|$ variation (corresponding to the feedback loop effect), one can observe that $|\alpha \mathrm{D}|$ reaches its maximum and $\left|K_{d e g} \mathrm{C} 8\right|$ its minimum at approximately the same moment, which also coincides with the moment when $\mathrm{C} 8$ starts increasing. Recall that $\alpha \mathrm{D}$ drives all the effective caspase cascade and the feedback loop, so the coincidence between maximum of $\alpha \mathrm{D}$ and beginning of $\mathrm{C} 8$ activation suggests that the feedback loop markedly increases the production of C8. Finally, observe that, in the absence 

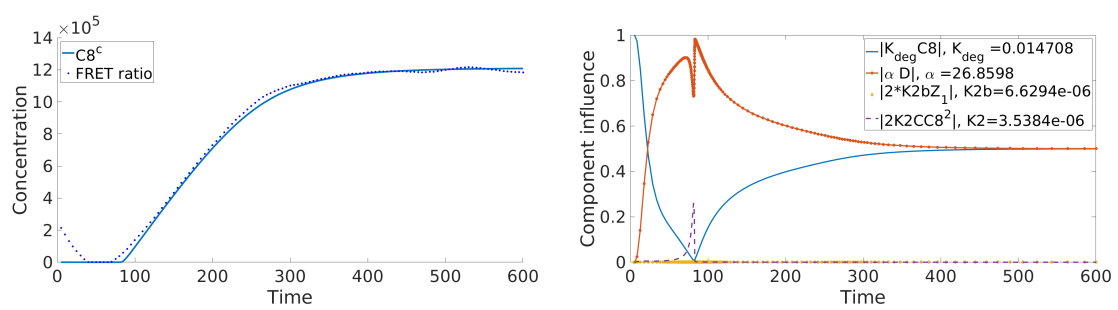

(a) Real FRET ratio and $C 8^{c}$ for EAICM-cf

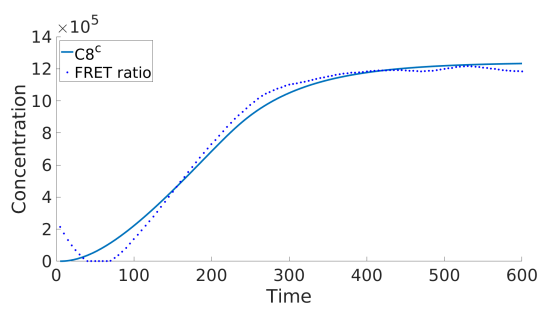

(b) C8 equation component dynamics for EAICM-cf

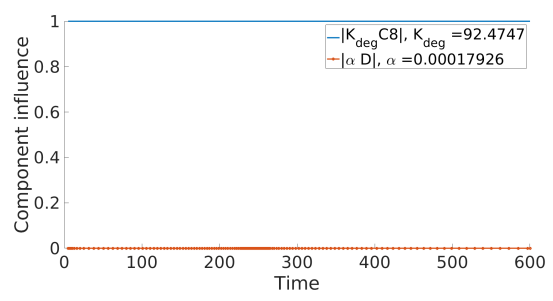

(c) Real FRET ratio and $C 8^{c}$ for (d) C8 equation component dynamics EAICM-c for EAICM-c

Fig. 3: Comparison of $\mathrm{C} 8$ dynamics and main properties for models EAICM-cf (a),(b) and EAICM-c (c),(d), for the resistant cell n. 10
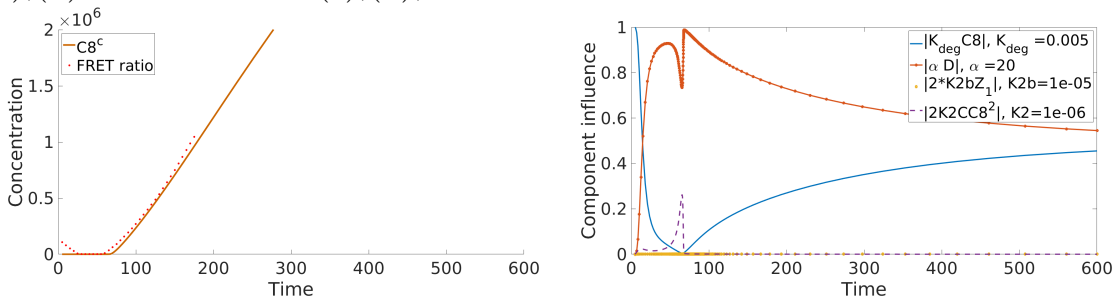

(a) Real FRET ratio and $C 8^{c}$ for EAICM-cf

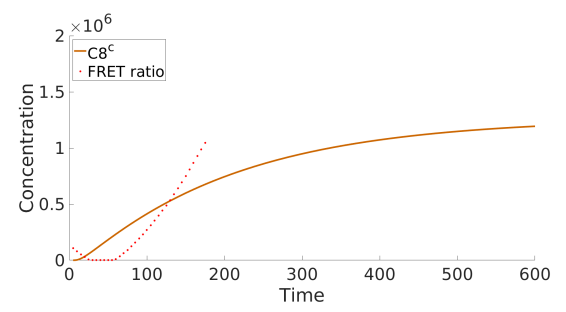

(b) C8 equation component dynamics for EAICM-cf

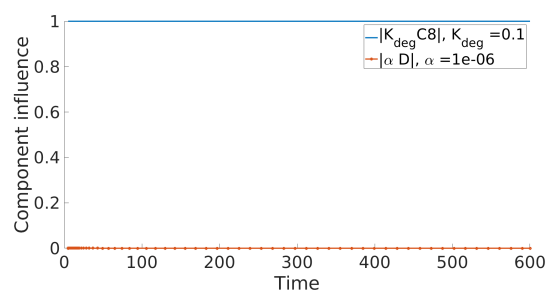

(c) Real FRET ratio and $C 8^{c}$ for

(d) C8 equation component dynamics EAICM-c for EAICM-c

Fig. 4: Comparison of $\mathrm{C} 8$ dynamics and main properties for models EAICMcf (a),(b) and EAICM-c (c),(d) for the sensitive cell n. 121 - simulations were performed for 600 min for comparison needs 
of feedback loop, the term $\left|K_{d e g} \mathrm{C} 8\right|$ is responsible for all the dynamics of C8, inducing similar activation slopes for the two phenotypes.

Overall, the feedback loop helps to refine cell decision, by improving modulation of the activation slope, as illustrated by the term $\alpha \mathrm{D}$ : for the sensitive cell, in the first 50 minutes $\alpha \mathrm{D}$ increases in a much steeper manner. The feedback represents a supplementary set of regulatory mechanisms that is surely independent from the complex TRAIL/receptors and possibly downstream, yet with a decisive impact on $\mathrm{C} 8$ activation.

The next step is evaluating the effect of variability in initial conditions on both $\mathrm{C} 8$ and cell fate.

\subsection{Initial conditions impacts on slope values}

This section analyses the initial conditions distributions and compares them with our reference values, to identify some mathematical patterns that can help predicting the cell fate. The goal is to find those distributions for which the resistant and sensitive phenotypes present a significant difference, or a link between the initial conditions and $\mathrm{C} 8$ dynamics.

To represent the data obtained after model's fitting, the bar chart of the cell density after model fitting according to their parameter distribution and the scatter plot of the initial condition distribution in logscale according to our reference values (for example, the slope) are used. For each type of graph, resistant and sensitive cells are differenciated to find specific behaviours.

The parameters used for comparison are those obtained from fit F3 (only on the initial conditions), to evaluate the environmental impacts. A clear difference for $\mathrm{C} 10_{0}$ between resistant and sensitive cells is observed on the logscale scatter plots in Figure 5 , with a linear correlation between the slope and the initial protein value with highly clustered points for the two types of cells. This is also the case for the $\mathrm{F}_{D}$ distribution that can be found in Figure 10 . To understand how

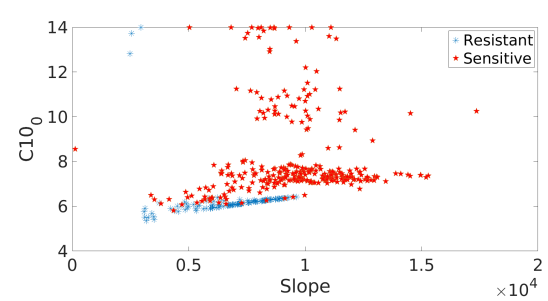

(a) EAICM-cf

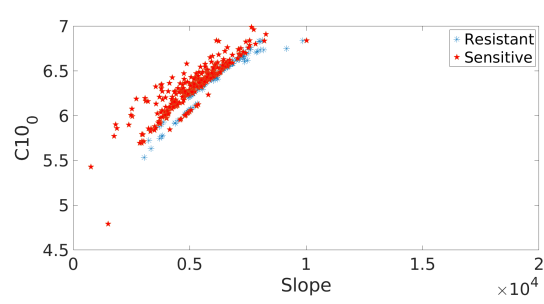

(b) EAICM-c

Fig. 5: Scatter plot of $C 10_{0}$ values according to the slope, depending on cell fate, for the EAICM-cf and EAICM-c

these two initial conditions, as well as $\mathrm{R}_{0}$ variation, affect the $\mathrm{C} 8$ dynamics, Figure 6 shows the evolution of the $\mathrm{C} 8^{c}$ curves for each model, as two of the initial conditions are fixed and the third is given by the median value obtained with the 
fit on all the parameters for resistant cells (given in appendix D in black dash dots on Figure 6) multiplied by $m \in\{0,0.2,0.4,0.6,0.8,1.2,1.4,1.6,1.8,2,4,10\}$.

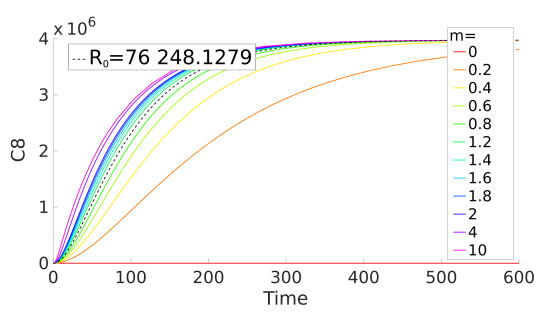

(a) EAICM-cf - $R_{0}$

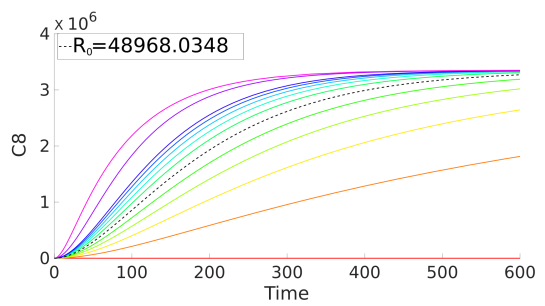

(c) EAICM-af - $R_{0}$

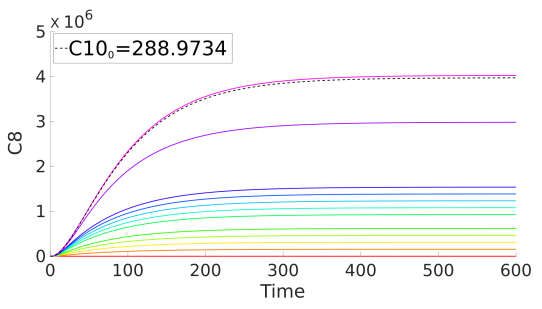

(e) EAICM-cf - $C 10_{0}$

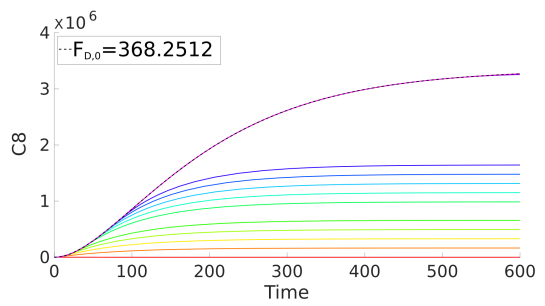

(g) EAICM-af - $F_{D, 0}$

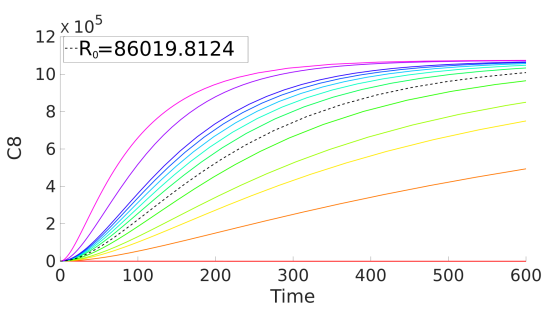

(b) EAICM-c - $R_{0}$

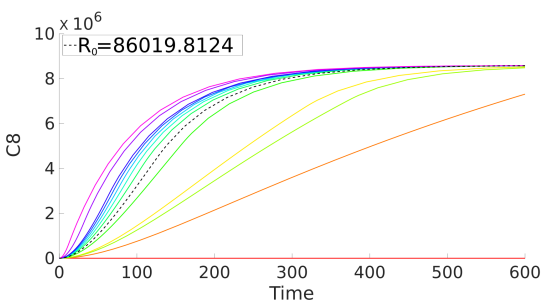

(d) EAICM-a - $R_{0}$

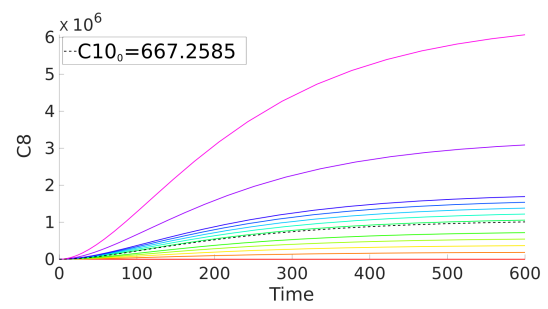

(f) EAICM-c - $C 10_{0}$

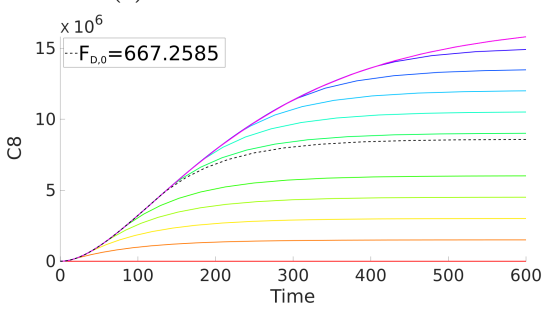

(h) EAICM-a - $F_{D, 0}$

Fig. 6: Initial condition variation effects on $\mathrm{C} 8$ dynamic. The estimated parameters $P_{i}$ are indicated at the top left corners and used as reference values to vary the initial condition, in the range $\left[0,10 X_{0}\right]$, where $X_{0}=\mathrm{R}_{0}$ in (a)-(d); $X_{0}=\mathrm{C} 10_{0}$ in (e)-(f); and $X_{0}=\mathrm{F}_{D, 0}$ in (g)-(h).

First of all, observe that an increase in the receptor number enhances the slope of $\mathrm{C} 8$ and so it speeds up the $\mathrm{C} 8$ production and delays the $\mathrm{C} 8$ degrada- 
tion since the stabilization happens later but it doesn't influence the total C8 production ( $\mathrm{C} 8$ stabilization at the same value). Hence, $\mathrm{R}_{0}$ is likely to contribute to determination of the $\mathrm{C} 8$ activation threshold.

A saturation effect is observed in every model, for the recruited C8, that can't exceed a certain threshold in the total C8 production. This is in agreement with single cell traces since, independently of the TRAIL dose, even at saturated concentration with all the receptors occupied, not every cell commits to apoptosis. An improvement in our models may be necessary to take into account the necessary receptors trimerization that leads to DISC formation [16].

Another observation is that larger $\mathrm{C}_{10} 0_{0}$ induce larger values for $\mathrm{C} 8$ stabilization. An increase in $\mathrm{C} 10_{0}$ enhances the $\mathrm{C} 8$ production speed but doesn't impact the degradation beginning time. Observe that $\mathrm{C} 10_{0}$ also plays a significant role in feedback loop-free models. This effect of $\mathrm{C}_{10}$ on $\mathrm{C} 8$ behaviour confirms the essential role of caspase cluster to trigger cell-death, as shown in Dickens and al. [16.

Finally, increasing $F_{D, 0}$ delays $\mathrm{C} 8$ degradation and improves $\mathrm{C} 8$ production or recruitment, but doesn't speed up the $\mathrm{C} 8$ production since the activation slope doesn't show much variation. Furthermore, increasing $F_{D, 0}$ leads to an increase in $\mathrm{C} 8$, thus making it possible to exceed the $\mathrm{C} 8$ threshold responsible for cell death and confirming that FADD is necessary to trigger the extrinsic cell death as demonstrated by Kuang and al. in [18. Similarly to $C 10_{0}, \mathrm{~F}_{D}$ also has more influence on the model without feedback loop, suggesting that the feedback loop has a saturation effect on $\mathrm{C} 8$ dynamic.

\subsection{Model validation and degradation specificity}

Comparison of the reaction rates distributions, singles out $\mathrm{C} 8$ degradation rate which exhibits a large discrepancy between resistant and sensitive populations, with values related by a factor $K_{d e g}^{r} \approx 10 K_{d e g}^{s}$.

As seen in Section 4.2 degradation is the process that counteracts C8 activation and, when the term $K_{d e g} C 8$ becomes sufficiently high, the stabilization phase sets in. Decreasing the degradation rate constant should lead to higher activation slopes and effectively "switch" cells from the resistant to the sensitive populations.

Data from [17 includes a second group of 563 cells treated with $50 \mathrm{ng} / \mathrm{mL}$ of TRAIL and $100 \mathrm{ng} / \mathrm{mL}$ of Bortezomib, a proteasome inhibitor drug that blocks C8 degradation and drives the cell to commit apoptosis. To validate our models, our hypothesis is that, setting $K_{d e g}$ to zero in model EAICM-cf (while keeping other parameters as estimated for each resistant cell), will elicit the same response as Bortezomib, thus transforming the resistant population into sensitive. Figure 7(a) shows the FRET ratio of the two groups of cells: the resistant population of 100 cells treated only with TRAIL and the second group of 563 cells treated with TRAIL and Bortezomib. These experimental results are to be compared with Figure 7(b), that represents the $\mathrm{C} 8^{c}$ EAICM-cf model curves for our 
original resistant population, with all the corresponding estimated parameters except for $K_{d e g}$, which is set to 0 .
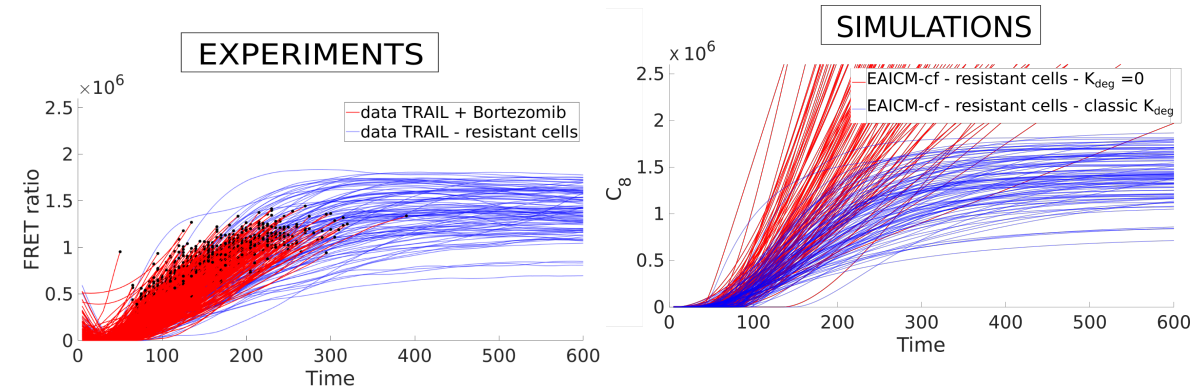

(b) Comparison of $C 8^{c}$ from EAICM-cf for (a) Comparison of FRET ratio between re- resistant cells treated only with TRAIL, sistant cells treated only with TRAIL and with $K_{d e g}=0$ and with classic degradacells treated with TRAIL and Bortezomib. tion.

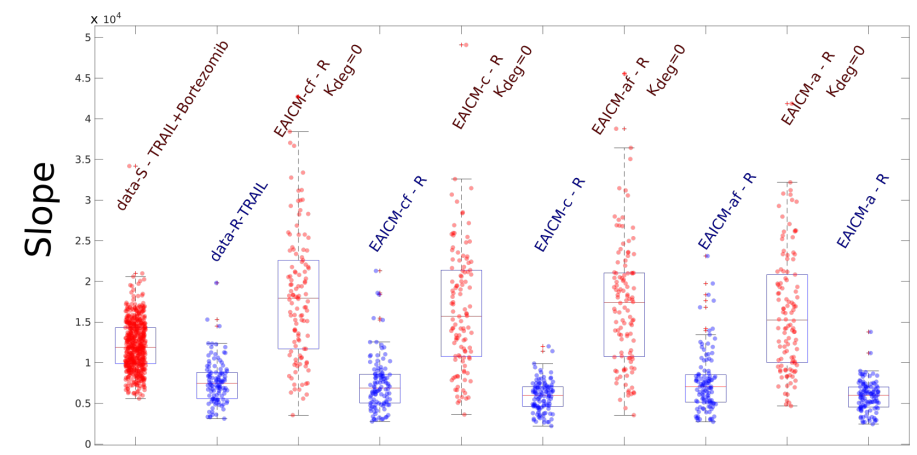

(c) Slope distribution according to the model used and the C8 degradation rate.

Fig. 7: Degradation study

Observe that the model predictions in Figure 7(b) and (c)

are quite similar to the experimental data. Figure 7

shows that, imposing a null degradation for our model, allows to reproduce a large heterogeneity range and the main features (delay and bigger slope) of C8 dynamic of the population treated with Bortezomib, thus validating our hypothesis.

Why does the sensitive population of the first group of cells show a markedly lower $K_{d e g}$ constant? Perhaps a (negative) feedback or similar mechanism is also acting on the degradation process, annulling its effect in the case of a steep C8 activation. However, it might be the case that the estimation of $K_{d e g}$ among the sensitive population is not fully reliable: indeed, recall that the degradation term is linear, $K_{d e g} \mathrm{C} 8$, and that active caspase 8 is absent at the beginning 
$(\mathrm{C} 8(0)=0)$, implying a very low degradation when compared to terms of the form $K_{2} Z_{1}$ or $\alpha \mathrm{D}$ which are proportional to $\mathrm{T}_{0} \mathrm{R}_{0}$. In addition, sensitive cells die relatively early during the first 150 minutes, so that there are much fewer measurement points available than for resistant cells. New modeling steps are needed to further study the C8 degradation process.

\section{Discussion and Conclusion}

This paper studies the role and the relevance of several components of the extrinsic apoptosis initiation pathway in cell response heterogeneity. Four minimal ODE models are proposed, taking into account the major steps of the extrinsic pathway: the TRAIL/receptors association, the DISC formation with the recruitment of pro-caspase 8 and, either a focus on the FADD action, or a particular attention to the cluster formation of $\mathrm{pC} 8$ and $\mathrm{pC} 10$. These models also represent the $\mathrm{C} 8$ activation with (or without) a positive feedback loop on $\mathrm{C} 8$ to integrate a supplementary regulation of $\mathrm{C} 8$ downstream. Finally, as cell decision to commit apoptosis seems to happen before effective caspase activation and MOMP, all the downstream apoptosis steps were combined in a single variable.

The models were calibrated to single cell data from a cloned population treated with death ligand TRAIL. The corresponding initial conditions and/or parameters were analysed to search for correlations between molecular factors and/or network interactions, and the resulting cell fates.

Our analysis selects two mechanisms that significantly contribute to cell response heterogeneity: the clusterization of the caspases C8/C10 and subsequent C8 activation and, to a larger extent, the positive feedback loop. The formation of $\mathrm{C} 8 / \mathrm{C} 10$ clusters accelerates $\mathrm{C} 8$ activation by increasing $\mathrm{C} 8$ production as well as the slope of the curve (see the effect of $\mathrm{C}_{10}$ ), while the $\mathrm{F}_{D}$ reaction does not greatly affect the slope but delays the stabilization time. Therefore, caspase clusterization has a greater capacity to generate variability in cell response.

The positive feedback is important in the timing of C8 dynamics, particularly in reproducing the initial delay observed in $\mathrm{C} 8$ activation. Studying the components of the $\mathrm{C} 8$ equation shows that activation of $\mathrm{C} 8$ is triggered when the feedback loop has a maximum effect on $\mathrm{C} 8$ and degradation is still negligible. Conversely, when the degradation and the feedback loop terms reach similar levels C8 leaves the high slope phase, revealing that the balance between feedback loop and $\mathrm{C} 8$ degradation plays a major role in cell fate.

Another role of the feedback loop is to introduce a saturation on the maximum level of C8 induced by variability in initial conditions: indeed, for our two models with positive feedback, increasing the initial numbers of molecules leads to an increase in the maximum $\mathrm{C} 8$ levels, but this maximum value has an upperbound independent of the initial numbers. This reveals a large robustness of the feedback models with respect to variations in initial amounts of molecules.

Finally, our models faithfully reproduce the experiments involving Bortezomib, a drug that blocks $\mathrm{C} 8$ degradation. In our models, application of Bortezomib is represented by setting $K_{d e g}=0$, and the corresponding effect is to 
increase all activation slopes into the range observed for the sensitive population. Based on the mechanisms and interactions selected by our methods, future work includes the development of a more detailed model to answer further questions such as the need for trimerization of the death receptor, understand the process of caspase degradation during the first hours of C8 activation, or adding new variables to investigate the impact of the anti-apoptotic component c-FLIP.

\section{References}

1. Matveeva, A., Fichtner, M., McAllister, K., McCann, C., Sturrock, M., Longley, D. B. and Prehn, J. HM : Heterogeneous responses to low level death receptor activation are explained by random molecular assembly of the Caspase- 8 activation platform. In PLoS computational biology, vol. 15, n. 9, p. e1007374. Public Library of Science, San Francisco, CA USA (2019)

2. Bouralexis, S., Findlay, DM. and Evdokiou, A.: Death to the bad guys: targeting cancer via Apo2L/TRAIL. In Apoptosis, vol.10, n.1, p. 35-51. Springer (2005)

3. Shlyakhtina, Y., Pavet, V. and Gronemeyer, H. : Dual role of DR5 in death and survival signaling leads to TRAIL resistance in cancer cells. In Cell death \& disease, vol. 8, n. 8, p. e3025. Nature Publishing Group (2017)

4. Eskes, R., Desagher, S., Antonsson, B., Martinou, JC. : Bid induces the oligomerization and insertion of Bax into the outer mitochondrial membrane. In Molecular and cellular biology, vol. 20, n. 3, p. 929-935.Am Soc Microbiol (2000)

5. Fricker, N., Beaudouin, J., Richter, P., Eils, R., Krammer, P. H. and Lavrik, I. N. : Model-based dissection of CD95 signaling dynamics reveals both a pro-and antiapoptotic role of c-FLIPL. In : The Journal of cell biology, vol. 190, n. 3, p. 377-389. Rockefeller University Press (2010)

6. Han, L., Zhao, Y., and Jia, X. : Mathematical modeling identified c-FLIP as an apoptotic switch in death receptor induced apoptosis. In Apoptosis, vol. 13 n. 10, p. 1198-1204. Springer (2008)

7. Tsuchiya, Y., Nakabayashi, O. and Nakano, H. : FLIP the Switch: Regulation of Apoptosis and Necroptosis by cFLIP. In International journal of molecular sciences, vol. 16, n. 12, p. 30321-30341. Multidisciplinary Digital Publishing Institute (2015)

8. Hughes, M. A., Powley, I.R., Jukes-Jones, R., Horn, S., Feoktistova, M., Fairall, L. Schwabe, J. WR., Leverkus, M., Cain, K. and MacFarlane, M. : Co-operative and hierarchical binding of c-FLIP and caspase-8: a unified model defines how c-FLIP isoforms differentially control cell fate. In Molecular cell, vol. 61, n. 6, p. 834-849. Elsevier (2016)

9. Hillert, L. K, Ivanisenko, N. V., Espe, J., König, Co., Ivanisenko, V. A.,Kähne, T.and Lavrik, I. N. : Long and short isoforms of c-FLIP act as control checkpoints of DED filament assembly. In Oncogene, vol. 39, n. 8, p.1756-1772. Nature Publishing Group (2020)

10. Horn, S. and Hughes, M. A., Schilling, R., Sticht, C. Tenev, T. Ploesser, M., Meier, P., Sprick, M. R., MacFarlane, M. and Leverkus, M.: Caspase-10 negatively regulates caspase-8-mediated cell death, switching the response to CD95L in favor of NF- $\kappa \mathrm{B}$ activation and cell survival. In Cell reports, vol. 19, n. 4, p. 785-797. Elsevier (2017)

11. Wang, Jin and Chun, Hyung J and Wong, Wilson and Spencer, David M and Lenardo, Michael J : Caspase-10 is an initiator caspase in death receptor signaling. In Proceedings of the National Academy of Sciences, vol. 98, n. 24, p. 13884-13888, National Acad Sciences (2001) 
12. Wachmann, Katherine and Pop, Cristina and van Raam, Bram J and Drag, Marcin and Mace, Peter D and Snipas, Scott J and Zmasek, Christian and Schwarzenbacher, Robert and Salvesen, Guy S and Riedl, Stefan J: Activation and specificity of human caspase-10. In Biochemistry, vol. 49, n. 38, p. 8307-8315, ACS Publications (2010)

13. Kischkel, Frank C and Lawrence, David A and Tinel, Antoine and LeBlanc, Heidi and Virmani, Arvind and Schow, Peter and Gazdar, Adi and Blenis, John and Arnott, David and Ashkenazi, Avi: Death receptor recruitment of endogenous caspase-10 and apoptosis initiation in the absence of caspase-8. In Journal of Biological Chemistry, vol. 276, n. 49, p. 46639-46646, ASBMB (2001)

14. Raulf, N and El-Attar, R and Kulms, D and Lecis, D and Delia, D and Walczak, H and Papenfuss, $\mathrm{K}$ and Odell, $\mathrm{E}$ and Tavassoli, M: Differential response of head and neck cancer cell lines to TRAIL or Smac mimetics is associated with the cellular levels and activity of caspase- 8 and caspase-10. In British journal of cancer, vol. 111, n. 10, p. 1955-1964, Nature Publishing Group (2014)

15. Kumari, Rajni and Deshmukh, Ruhi S and Das, Sanjeev: Caspase-10 inhibits ATPcitrate lyase-mediated metabolic and epigenetic reprogramming to suppress tumorigenesis. In Nature communications, vol. 10, n. 1, p. 1-15,Nature Publishing Group (2019)

16. Dickens, L. S., Boyd, R. S. and Jukes-Jones, R., Hughes, M. A., Robinson, G. L., Fairall, L., Schwabe, J. WR., Cain, Kelvin and MacFarlane, Marion : A death effector domain chain DISC model reveals a crucial role for caspase- 8 chain assembly in mediating apoptotic cell death. In Molecular cell, vol.47, n. 2, p. 291-305 . Elsevier (2012)

17. Roux, J., Hafner, M., Bandara, S., Sims, J. J., Hudson, H., Chai, D.and Sorger, P. K. : Fractional killing arises from cell-to-cell variability in overcoming a caspase activity threshold. In Molecular systems biology, vol. 11, n. 5. John Wiley \& Sons, Ltd (2015)

18. Kuang, A.A., Diehl, G. E., Zhang, J. and Winoto, Astar : FADD is required for DR4-and DR5-mediated apoptosis 1ACK of TRAIL-induced apoptosis in FADDdeficient mouse embryonic fibroblasts. In Journal of Biological Chemistry, vol. 275, n. 33, p.25065-25068. ASBMB (2000)

19. Chang, D. W., Xing, Z., Capacio, V. L., Peter, M. E. and Yang, X. : Interdimer processing mechanism of procaspase- 8 activation. In The EMBO journal, vol.22, n. 16, p. 4132-4142. John Wiley \& Sons, Ltd (2003)

20. Schleich, K and Buchbinder, JH and Pietkiewicz, S and Kähne, T and Warnken, U and Öztürk, S., Schnölzer, M., Naumann, M., Krammer, P. H. and Lavrik, IN. : Molecular architecture of the DED chains at the DISC: regulation of procaspase8 activation by short DED proteins c-FLIP and procaspase- 8 prodomain. In Cell death and differentiation, vol. 23, n. 4, p. 681. Nature Publishing Group (2016)

21. Albeck, J. G., Burke, J. M., Spencer, S. L., Lauffenburger, D. A. and Sorger, P. K. : Modeling a snap-action, variable-delay switch controlling extrinsic cell death. In PLoS biology, vol.6, n. 12, p. e299. Public Library of Science (2008)

22. Lederman, E. E.Hope, J. M. and King, M. R. : Mass Action Kinetic Model of Apoptosis by TRAIL-Functionalized Leukocytes. In Frontiers in oncology, vol. 8. Frontiers Media SA (2018)

23. Bertaux, F., Stoma, S., Drasdo, D. and Batt, G. : Modeling dynamics of cell-tocell variability in TRAIL-induced apoptosis explains fractional killing and predicts reversible resistance. In PLoS computational biology, vol. 10, n. 10, p. e1003893. Public Library of Science (2014) 
24. Chong, K. H., Samarasinghe, S., Kulasiri, D. and Zheng, J. : Mathematical modelling of core regulatory mechanism in p53 protein that activates apoptotic switch. In Journal of theoretical biology, vol. 462, p. 134-147. Elsevier (2019)

25. Ballweg, R., Paek, A. L .and Zhang, T.: A dynamical framework for complex fractional killing. In Scientific reports, vol.7, n. 1, p. 8002. Nature Publishing Group (2017)

26. Buchbinder, J. H., Pischel, D., Sundmacher, K., Flassig, R. J. and Lavrik, I. N. : Quantitative single cell analysis uncovers the life/death decision in CD95 network. In PLoS computational biology, vol. 14, n. 9, p. e1006368. Public Library of Science (2018)

27. Bentele, M., Lavrik, I., Ulrich, M., Stösser, S., Heermann, DW., Kalthoff, H., Krammer, P. H. and Eils, R.: Mathematical modeling reveals threshold mechanism in CD95-induced apoptosis. In J Cell Biol, vol. 166, n. 6, p. 839-851. Rockefeller University Press (2004)

28. Neumann, L., Pforr, C., Beaudouin, J., Pappa, A., Fricker, N., Krammer, P. H., Lavrik, I. N. and Eils, R. : Dynamics within the CD95 death-inducing signaling complex decide life and death of cells. In Molecular systems biology, vol. 6, n.1. John Wiley \& Sons, Ltd (2010)

29. Paek, A. L., Liu, J. C., Loewer, A., Forrester, W.C. and Lahav, G. : Cell-to-cell variation in p53 dynamics leads to fractional killing. In Cell, vol. 165, n. 3, p. 631642. Elsevier (2016)

30. Rehm, M., Huber, H. J., Dussmann, H. and Prehn, J. HM. : Systems analysis of effector caspase activation and its control by X-linked inhibitor of apoptosis protein. In The EMBO journal, vol.25, n. 18, p. 4338-4349. John Wiley \& Sons, Ltd (2006)

31. Martin D. A. Siegel, R. M., Zheng, L. and Lenardo, M. J. : Membrane oligomerization and cleavage activates the caspase-8 (FLICE/MACH $\alpha 1$ ) death signal. In Journal of Biological Chemistry, v. 273, n. 8, p. 4345-4349. ASBMB (1998)

32. Fallahi-Sichani, M., Honarnejad, S., Heiser, L. M., Gray, J.W. and Sorger, P. K. : Metrics other than potency reveal systematic variation in responses to cancer drugs. In Nature chemical biology, v. 9, n. 11, p. 708. Nature Publishing Group (2013)

33. Flusberg, D. A., Roux, J. and Spencer, S. L., and Sorger, P. K. : Cells surviving fractional killing by TRAIL exhibit transient but sustainable resistance and inflammatory phenotypes. In Molecular biology of the cell, vol. 24, n. 14, p. 2186-2200. Am Soc Cell Biol (2013)

34. Casagranda, S., Touzeau, S., Ropers, D. and Gouzé, JL. : Principal process analysis of biological models. In BMC systems biology, vol. 12, n.1, p. 68. Springer (2018)

35. Hillert, L. K and Ivanisenko, N. V , Busse, D. , Espe, J. , König, C. , Peltek, S. E , Kolchanov, N. A ,Ivanisenko, V. A and Lavrik, Inna N : Dissecting DISC regulation via pharmacological targeting of caspase-8/c-FLIP L heterodimer. In Cell Death \& Differentiation. p.1-14, Nature Publishing Group (2020)

36. Schwarzer, R., Jiao, H., Wachsmuth, L. Tresch, A. and Pasparakis, M. :FADD and Caspase- 8 Regulate Gut Homeostasis and Inflammation by Controlling MLKL-and GSDMD-Mediated Death of Intestinal Epithelial Cells. In Immunity, Elsevier(2020)

37. Strasser, Andreas and Vaux, David L : Cell Death in the Origin and Treatment of Cancer. In Molecular Cell, Elsevier(2020)

38. Tummers, Bart and Mari, Luigi and Guy, Clifford S and Heckmann, Bradlee L and Rodriguez, Diego A and Rühl, Sebastian and Moretti, Julien and Crawford, Jeremy Chase and Fitzgerald, Patrick and Kanneganti, Thirumala-Devi and others : Caspase-8-Dependent Inflammatory Responses Are Controlled by Its Adaptor, FADD, and Necroptosis. In Immunity, Elsevier (2020) 
39. Amaral, Marcelo Pires and Bortoluci, Karina Ramalho : Caspase- 8 and FADD: Where Cell Death and Inflammation Collide. In Immunity, vol. 52, n. 6, p.890-892, Elsevier(2020)

40. Chaudhry, M Zeeshan and Casalegno-Garduno, Rosaely and Sitnik, Katarzyna M and Kasmapour, Bahram and Pulm, Ann-Kathrin and Brizic, Ilija and Eiz-Vesper, Britta and Moosmann, Andreas and Jonjic, Stipan and Mocarski, Edward S and others : Cytomegalovirus inhibition of extrinsic apoptosis determines fitness and resistance to cytotoxic CD8 T cells. In Proceedings of the National Academy of Sciences, vol. 117, n.23, p.12961-12968, National Acad Sciences (2020)

41. Llamosi, Artémis and Gonzalez-Vargas, Andres M and Versari, Cristian and Cinquemani, Eugenio and Ferrari-Trecate, Giancarlo and Hersen, Pascal and Batt, Gregory : What population reveals about individual cell identity: single-cell parameter estimation of models of gene expression in yeast. In PLoS computational biology, vol.12, n.2, p.e1004706, Public Library of Science San Francisco, CA USA (2016)

42. Pereira, Luis Carlos Gomes : Thesis : Modeling cell response heterogeneity to proapoptotic ligands. COMUE Université Côte d'Azur (2015-2019) 


\section{Appendices}

\section{A Comparison models tables}

\begin{tabular}{|c|c|c|c|c|c|c|}
\hline \multirow{2}{*}{ F1 } & fate & EAICM-cf & EAICM-c & EAICM-af & EAICM-a & Best model \\
\cline { 2 - 8 } & S. cells & 177 & 20 & 95 & 8 & EAICM-cf \\
\cline { 2 - 8 } & R. cells & 51 & 3 & 52 & 8 & EAICM-cf/EAICM-af \\
\hline \multirow{2}{*}{ F2 } & S. cells & 0 & 20 & 0 & 280 & EAICM-a \\
\cline { 2 - 8 } & R. cells & 0 & 102 & 0 & 12 & EAICM-c \\
\hline \multirow{2}{*}{ F3 } & S. cells & 0 & 63 & 1 & 236 & EAICM-a \\
\cline { 2 - 8 } & R. cells & 2 & 95 & 0 & 17 & EAICM-c \\
\hline
\end{tabular}

Table 2: Number of cell best approached per model and type of fits, comparing $\mathcal{C}$ value

\begin{tabular}{|c|c|c|c|c|c|c|}
\hline Fit Model & fate & EAICM-cf & EAICM-c & EAICM-af & EAICM-a & Best model \\
\hline \multirow{2}{*}{$\mathrm{F} 1$} & S. cells & 132 & 98 & 20 & 50 & EAICM-cf \\
\hline & R. cells & 46 & 43 & 9 & 16 & EAICM-cf \\
\hline \multirow{2}{*}{$\mathrm{F} 2$} & S. cells & 130 & 103 & 8 & 59 & EAICM-cf \\
\hline & R. cells & 55 & 48 & 1 & 10 & EAICM-cf \\
\hline \multirow{2}{*}{ F3 } & S. cells & 222 & 20 & 17 & 41 & EAICM-cf \\
\hline & R. cells & 64 & 10 & 33 & 7 & EAICM-cf \\
\hline
\end{tabular}

Table 3: Number of cell best approached per model and type of fits comparing the delay, ie $\left|T_{100000, E A I C M, i}-T_{100000, \text { data }, i}\right|, i \in\{1, \ldots, 414\}$ 


\begin{tabular}{|c|c|c|c|c|c|l|}
\hline \multirow{2}{*}{ F1 Model } & fate & EAICM-cf & EAICM-c & EAICM-af & EAICM-a & Best model \\
\cline { 3 - 8 } & S. cells & 91 & 108 & 46 & 55 & EAICM-c \\
\cline { 2 - 8 } & R. cells & 45 & 16 & 35 & 18 & EAICM-cf \\
\hline \multirow{2}{*}{ F2 } & S. cells & 68 & 111 & 59 & 62 & EAICM-c \\
\cline { 2 - 8 } & R. cells & 51 & 10 & 44 & 9 & EAICM-cf \\
\hline \multirow{2}{*}{ F3 } & S. cells & 263 & 0 & 23 & 14 & EAICM-cf \\
\cline { 2 - 8 } & R. cells & 9 & 26 & 62 & 17 & EAICM-af \\
\hline
\end{tabular}

Table 4: Number of cell best approached per model and type of fits according to C8 final value, ie comparing $\left|V_{\text {final }, E A I C M, i}-V_{\text {final,data, } i}\right|, i \in\{1, \ldots, 414\}$

\section{B Feedback loop effects for EAICM-af and EAICM-a}

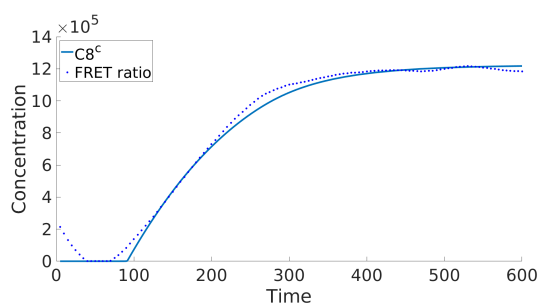

(a) Real FRET ratio and $C 8^{c}$ for EAICM-af

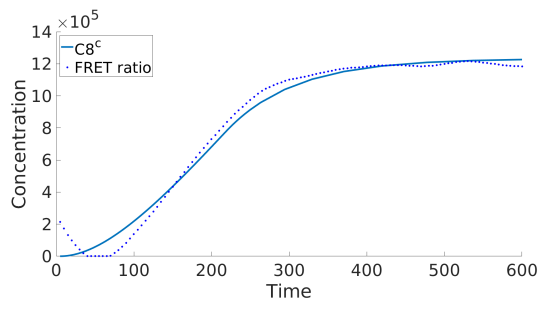

(c) Real FRET ratio and $C 8^{c}$ for EAICM-a

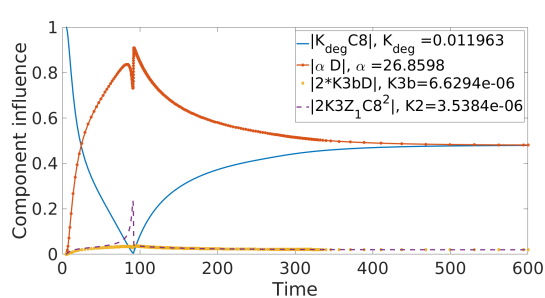

(b) C8 equation component dynamics for EAICM-af

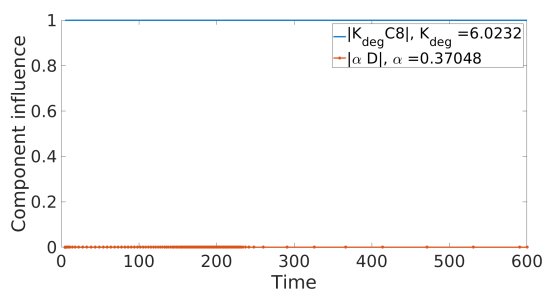

(d) C8 equation component dynamics for EAICM-a

Fig. 8: Comparison of C8 main features with the dynamic of each C8 equation component of EAICM-af (a),(b) and EAICM-a (c),(d) for the resistant cell n. 10 

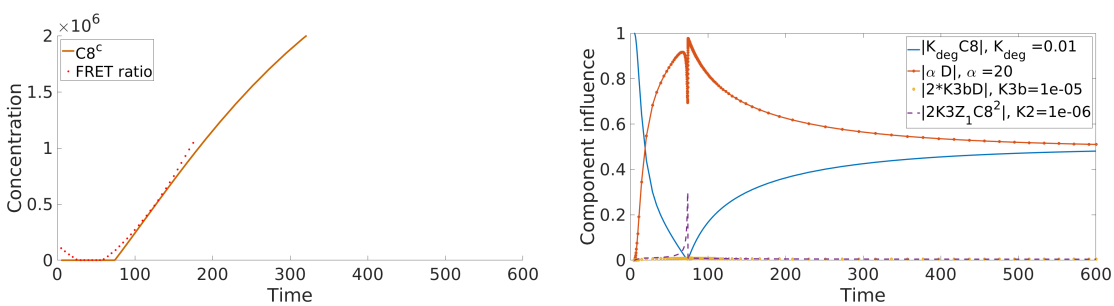

(a) Real FRET ratio and $C 8^{c}$ for EAICM-af

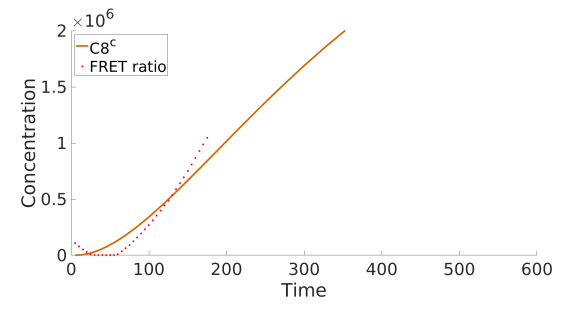

(b) C8 equation component dynamics for EAICM-af

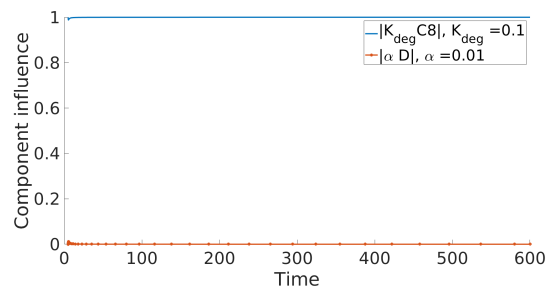

(c) Real FRET ratio and $C 8^{c}$ for (d) C8 equation component dynamics EAICM-a for EAICM-a

Fig. 9: Comparison of $\mathrm{C} 8$ main features with the dynamic of each $\mathrm{C} 8$ equation component of EAICM-af (a),(b) and EAICM-a (c),(d) for the sensitive cell $\mathrm{n}$. 121 - simulations were performed for 600 min for comparison needs

\section{Initial condition and cell fate correlations for EAICM-af}

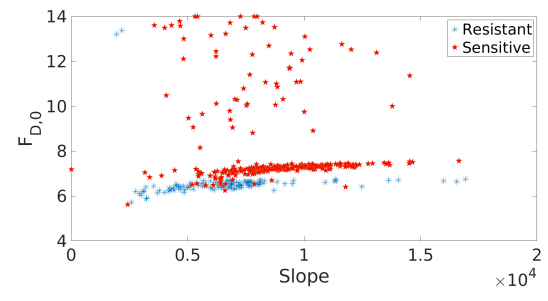

(a) EAICM-af

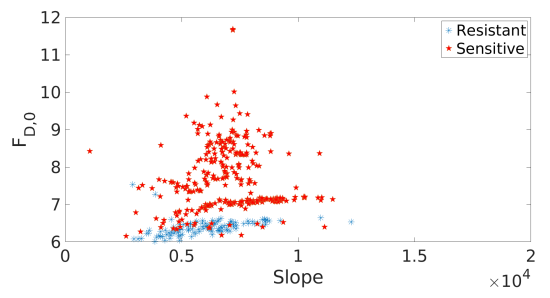

(b) EAICM-a

Fig. 10: Scatter plot of $F_{D, 0}$ values according to the slope, depending on the cell fate for EAICM-af and EAICM-a 


\section{Median parameter values from the fit on both initial conditions and reaction rates used in Figure 6}

\begin{tabular}{|c|c|c|c|c|c|c|c|c|}
\hline & \multicolumn{2}{|c|}{ EAICM-cf } & \multicolumn{2}{|c|}{ EAICM-c } & \multicolumn{2}{|c|}{ EAICM-af } & \multicolumn{2}{|c|}{ EAICM-a } \\
\hline & R. cells & S. cells & R. cells & S. cells & R. cells & S. cells & R. cells & S. cells \\
\hline $\overrightarrow{K_{1}}$ & $4.3955 \mathrm{e}-07$ & $2.7388 \mathrm{e}-07$ & $6.5892 \mathrm{e}-08$ & $1.2254 \mathrm{e}-07$ & $1.6320 \mathrm{e}-07$ & $4.0018 \mathrm{e}-07$ & $6.5892 \mathrm{e}-08$ & $1.2254 \mathrm{e}-07$ \\
\hline$\overleftarrow{K}_{1}$ & 0.0052 & 0.01129 & 1.1176 & 1.7906 & $3.4358 \mathrm{e}-04$ & 0.0011 & 1.1177 & 1.7907 \\
\hline$\vec{K}_{2}$ & $1.5590 \mathrm{e}-05$ & $2.4304 \mathrm{e}-05$ & & & 0.0525 & 0.0649 & 25.5081 & 14.8725 \\
\hline$\overleftarrow{K}_{2}$ & $2.9114 \mathrm{e}-04$ & $9.6920 \mathrm{e}-04$ & & & $3.6929 \mathrm{e}-06$ & $1.2142 \mathrm{e}-05$ & 2.3934 & 2.1489 \\
\hline$\vec{K}_{3}$ & 0.0012 & 0.002792 & 0.002045 & 0.002206 & $4.5915 \mathrm{e}-05$ & $2.1800 \mathrm{e}-04$ & & \\
\hline$\overleftarrow{K}_{3}$ & 0.0273 & 0.1607 & 20.1550 & 26.9179 & 2.0294 & 9.2971 & & \\
\hline$\vec{K}_{4}$ & & & 16.5523 & 25.6951 & & & 16.5524 & 25.6952 \\
\hline$\overleftarrow{K}_{4}$ & & & 2.6201 & 2.6749 & & & 2.6202 & 2.6750 \\
\hline$K_{\text {deg }}$ & 0.0133 & 0.004012 & 0.0001165 & 0.001765 & 0.0122 & 0.0108 & 0.0117 & 0.0018 \\
\hline$\alpha$ & 36.2215 & 48.8287 & 1.3188 & 279.2583 & 27.3338 & 76.6511 & 131.8895 & 279.2584 \\
\hline$R_{0}$ & $7.6248 \mathrm{e}+04$ & $6.7850 \mathrm{e}+04$ & $8.6019 e+04$ & $4.0387 \mathrm{e}+04$ & $4.8968 \mathrm{e}+04$ & $5.6593 \mathrm{e}+04$ & $8.6020 \mathrm{e}+04$ & $4.0388 \mathrm{e}+04$ \\
\hline$C_{8,0}$ & 288.9734 & 905.9665 & 667.2585 & 337.2630 & 368.2512 & 663.5847 & 667.2585 & 337.2631 \\
\hline$C_{10,0}$ & $2.2325 \mathrm{e}+03$ & $3.1050 \mathrm{e}+04$ & 761.9486 & $1.0829 \mathrm{e}+04$ & & & & \\
\hline$F_{D, 0}$ & & & & & $2.9291 \mathrm{e}+03$ & $5.3681 \mathrm{e}+04$ & 761.9486 & $1.0830 \mathrm{e}+04$ \\
\hline
\end{tabular}

Table 5: Median reaction rates and initial conditions for all models determined with the fit on both initial conditions and reactions rates

\section{E Operation of the parameter model and reference value tables}

In addition of this article,, we provide all the parameters tables and the reference values tables obtained with our 3 types of fit for the 414 cells treated with TRAIL only. A line corresponds to one parameter in that order $\left(\mathcal{C}, \vec{K}_{1}, \overleftarrow{K_{1}}, \vec{K}_{2}, \overleftarrow{K}_{2}, \vec{K}_{3}, \overleftarrow{K_{3}}, \vec{K}_{4}, \overleftarrow{K}_{4}, \alpha, K_{d e g}, R_{0}, C 8_{0}, C 10_{0}\right.$ 
or $\left.F_{D, 0}\right)$ and without $\vec{K}_{4}$ and $\overleftarrow{K}_{4}$ for models with feedback loop.

Parameters_EAICM-cf_NON_resist_fit_Pr_only.mat Parameters_EAICM-c_NON_resist_fit_Pr_only.mat Parameters_EAICM-af_NON_resist_fit_Pr_only.mat Parameters_EAICM-a_NON_resist_fit_Pr_only.mat
$12 \times 300$ table that gives the 8 reactions rates (10 for models without feedback loop) in the first lines and the 3 initial conditions obtained from the fit only on reaction rates for the 300 sensitive cells for each model in the last lines.
Parameters_EAICM-cf_resist_fit_Pr_only.mat Parameters_EAICM-c_resist_fit_Pr_only.mat Parameters_EAICM-af_resist_fit_Pr_only.mat Parameters_EAICM-a_resist_fit_Pr_only.mat
$12 \times 300$ table that gives the 8 reactions rates (10 for models without feedback loop) in the first lines and the 3 initial conditions obtained from the fit only on reaction rates for the 114 resistant cells for each model in the last lines.
Parameters_EAICM-cf_NON_resist_fit_Pi_only.mat Parameters_EAICM-c_NON_resist_fit_Pi_only.mat Parameters_EAICM-af_NON_resist_fit_Pi_only.mat Parameters_EAICM-a_NON_resist_fit_Pi_only.mat
$12 \times 300$ table that gives the 8 reactions rates (10 for models without feedback loop) in the first lines and the 3 initial conditions obtained from the fit only on intial conditions for the 300 sensitive cells for each model in the last lines.
Parameters_EAICM-cf_resist_fit_Pi_only.mat Parameters_EAICM-c_resist_fit_Pi_only.mat Parameters_EAICM-af_resist_fit_Pi_only.mat Parameters_EAICM-a_resist_fit_Pi_only.mat
$12 \times 300$ table that gives the 8 reactions rates (10 for models without feedback loop) in the first lines and the 3 initial conditions obtained from the fit only on initial conditions for the 114 resistant cells for each model in the last lines.
Parameters_EAICM-cf_NON_resist_fit_Pi_Pr.mat Parameters_EAICM-c_NON_resist_fit_Pi_Pr.mat Parameters_EAICM-af_NON_resist_fit_Pi_Pr.mat Parameters_EAICM-a_NON_resist_fit_Pi_Pr.mat
$12 \times 300$ table that gives the 8 reactions rates (10 for models without feedback loop) in the first lines and the 3 initial conditions obtained from the fit on both reaction rates and initial conditions for the 300 sensitive cells for each model in the last lines.
Parameters_EAICM-cf_resist_fit_Pi_Pr.mat Parameters_EAICM-c_resist_fit_Pi_Pr.mat Parameters_EAICM-af_resist_fit_Pi_Pr.mat Parameters_EAICM-a_resist_fit_Pi_Pr.mat
$12 \times 300$ table that gives the 8 reactions rates (10 for models without feedback loop) in the first lines and the 3 initial conditions obtained from the fit on both reaction rates and intial conditions for the 114 resistant cells for each model in the last lines.

With the same classification, the files that begin by "Reference_value" followed by the model's name, the cell fate ("resist" or "NON_resist") and the type of fit ("Pr_only", "Pi_only", "Pi_Pr"), contained 3 lines that gives the value of the slope, the C8 final value and the delay with $T_{100000}$ in this order with as many columns as cells. 